اثر ييشتيمار بذر با محلول سيليسيك اسيد و سديم نيترويروسايد بر جوانهزنى و رشد دانهال كوجهفرنكى گلخانهاى (Lycopersicon esculentum L. cv. Isabella) در شرايط تنش شورى

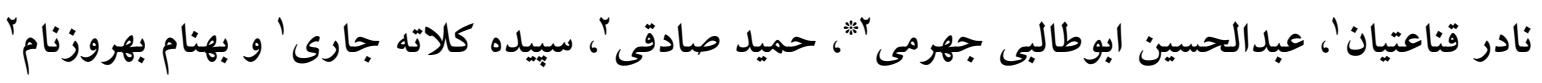

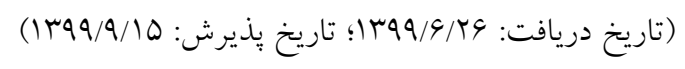

جكيده

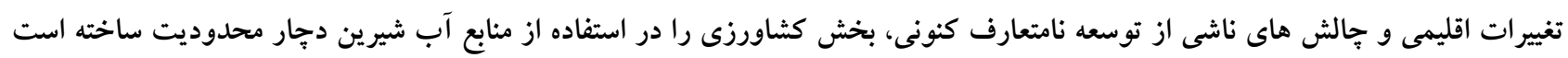

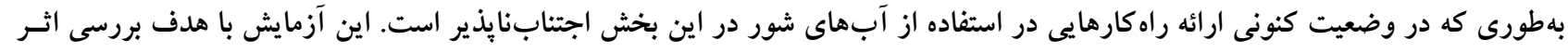

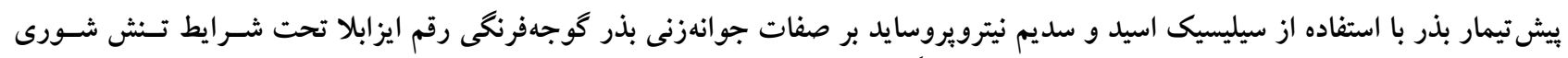

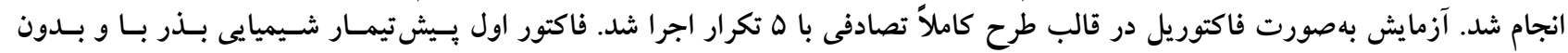

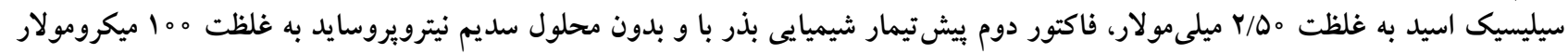

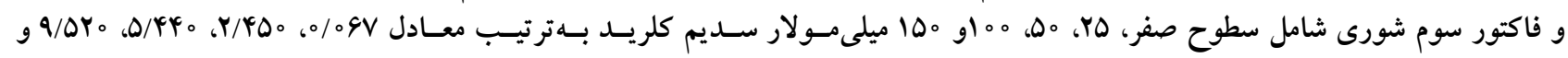

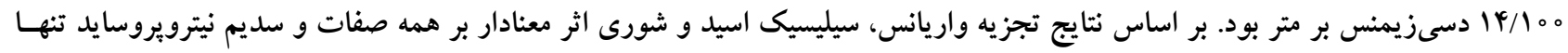

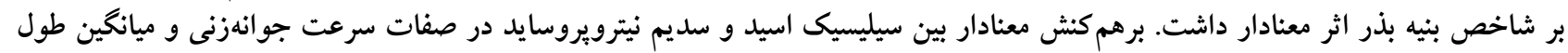

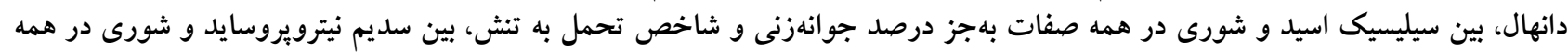

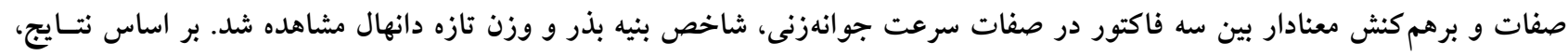

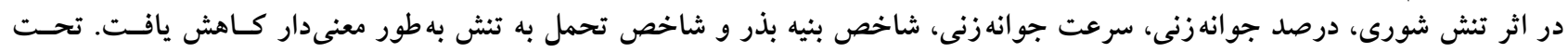

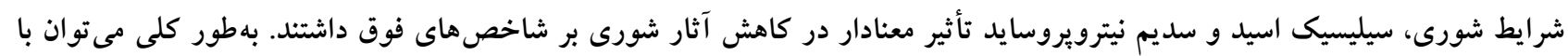

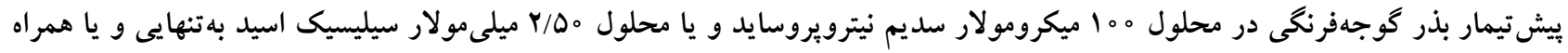

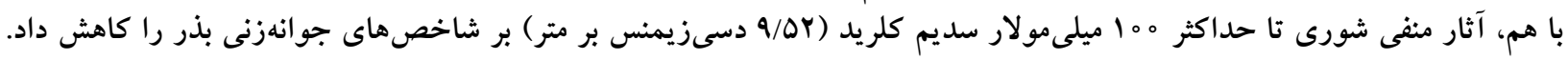

وازههاى كليدى: درصد جوانهزنى، سرعت جوانهزنى، شاخص بنيه بذر، شاخص تحمل به تنش

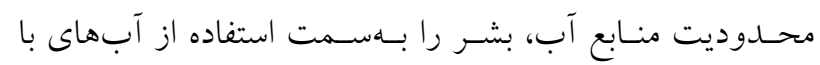

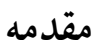

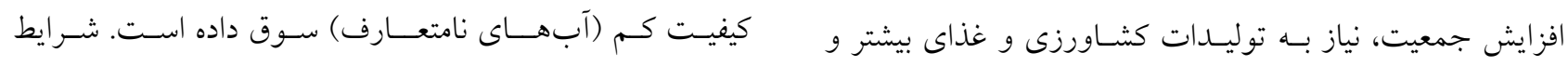

1- كروه علوم باغبانى، واحد علوم و تحقيقات، دانشخاه آزد اسلامى، تهران، ايران

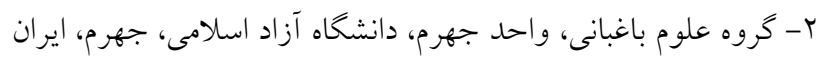

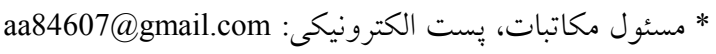


باعث افزايش درصد جوانهزنسى در كياهـان كنــدم تحـت تـنش

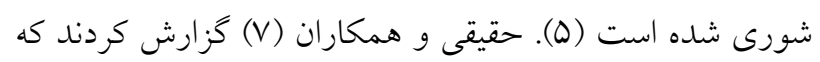

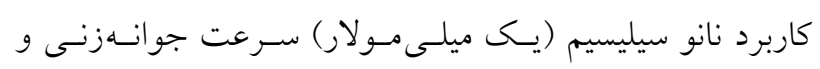
درصد جوانهزنى بذر كوجهفرنخى را در شورى مه ميلسى مـولار نسبت به بذور تيمارنشده با سيلسيم افزايش داد. نيتريك اكسيد

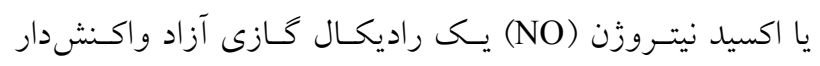

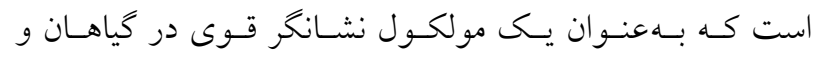
جانوران عمل مى كند. نيتريك اكسيد نقـش مهمسى را در تنظيم

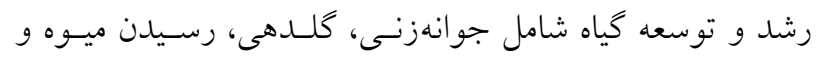

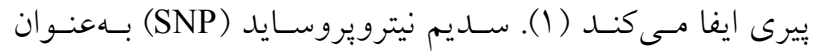

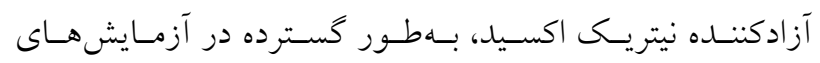
جوانهزنى بذر استفاده شده است. فرض بر ايسن اسـت كـه NO

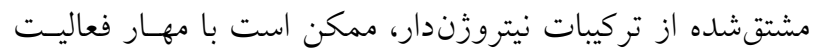

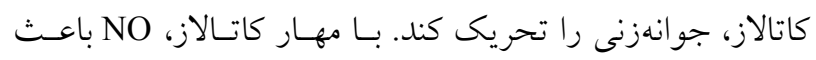

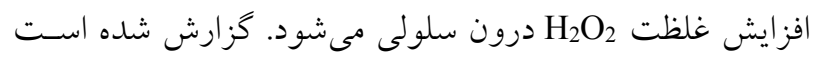

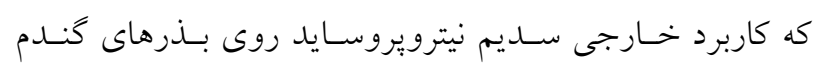

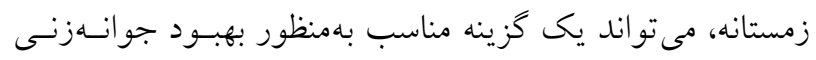

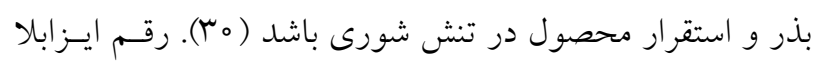

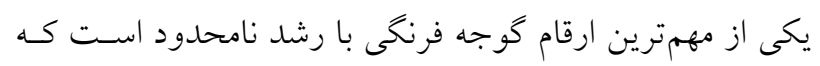

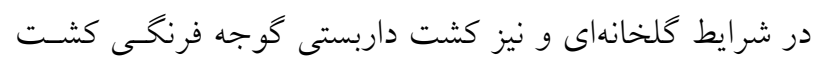

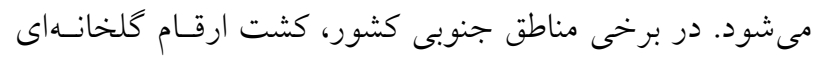

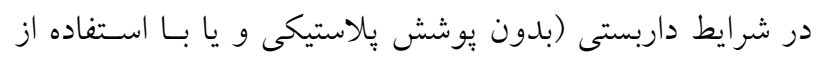

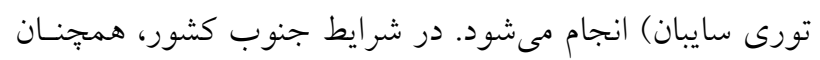
در برخى مناطق، مشكل دسترسى بــهـ آب شـيرين و يـا دسـتشاه

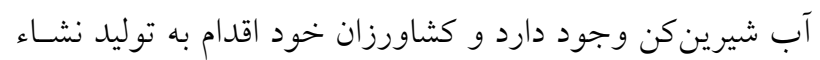

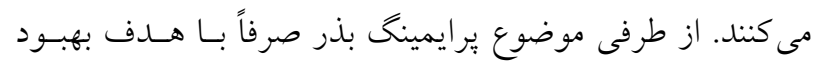

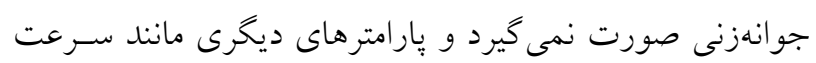
جو انهزنى، قدرت بذر و رشد رويشى دانهال نيز مد نظـر اسـت دئ.

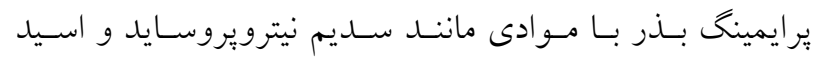

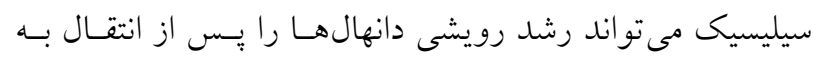

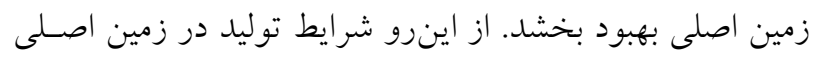
هميشه با آب شـيرين نبـوده و كـاهى در مقــادير شـورى زيساد
اقليمى و زمينهاى كشاورزى در بيشتر مناطق ايران بـهـونـهاى

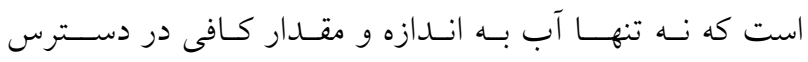

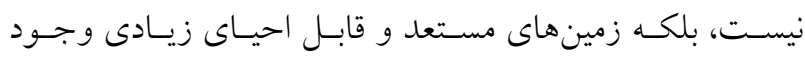

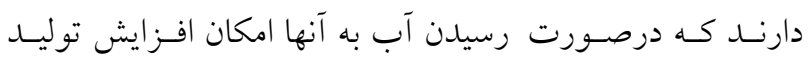
قابل توجهى وجود خواهد داشت. همجزنين بهدليل كمبود منـابع

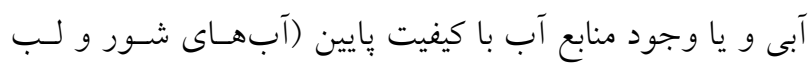

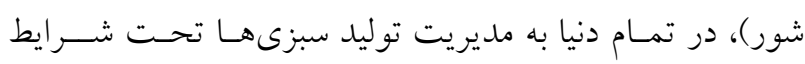

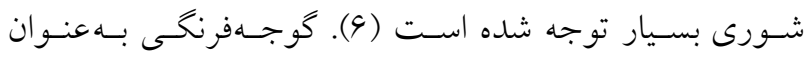

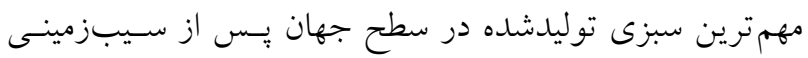

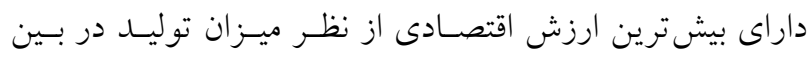

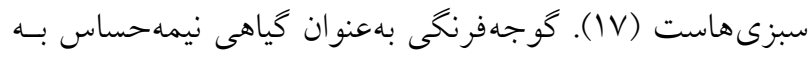

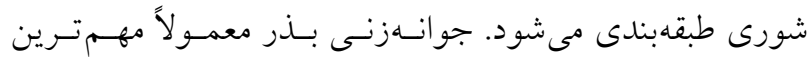

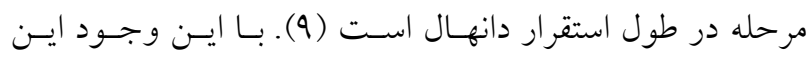

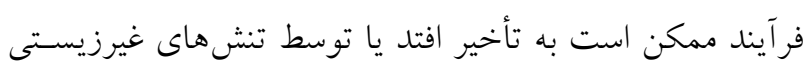

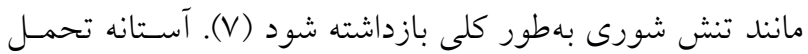

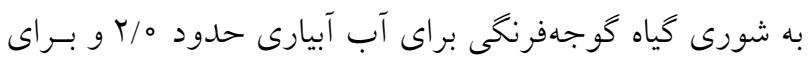

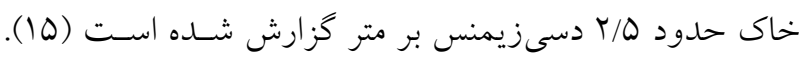
تنش شورى باعث جلـو كيرى از جوانسهزنسى بـــرها مسى شـوده،

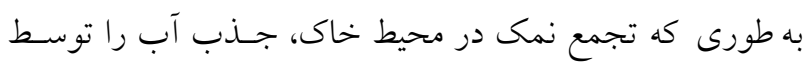

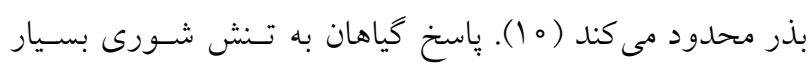

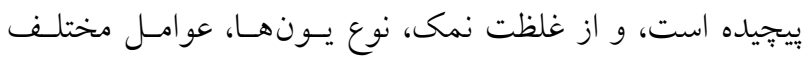

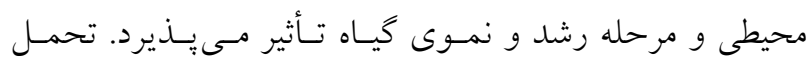

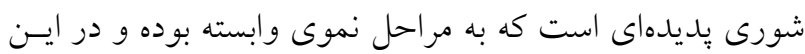
مر احل تنظيم مىشود (19).

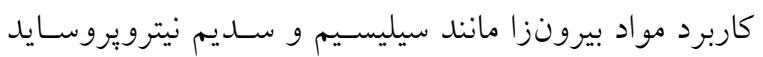

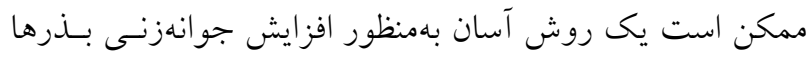
در شر ايط تنش شورى باشد. سيليسيم (Si) دومين عنصر فراوان در هسته زمين و عنصرى مورد نياز در تعدادى از فعاليـتهـاى متابوليكى و فعاليـتهـاى فيزيولـوزيكى در كياهـان اسـت (r). اكرجه اين عنصر جزء عناصر ضرورى كياه محسوب نمى شـود،

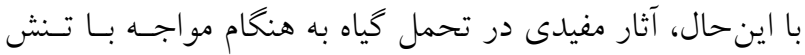

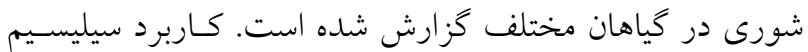




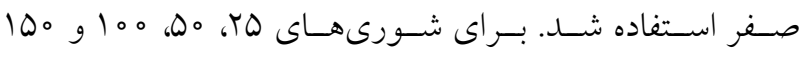

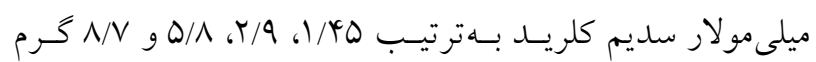
نمك طعام با آب مقطر به حجـم ليتـر رسـانده شـد. بـهمنظـور كاهش تبخير آب، درب بترى ديشها بسته و در اتـاق رشــ بـا بـا

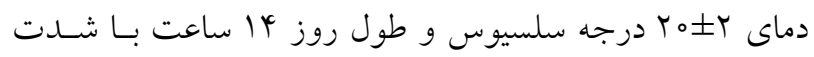
نور حدود هب هزار لوكس بهمدت عا إ روز قرار داده شدند و در پايان دوره نسبت به ثبت اطلاعات زير اقدام شد. درصد جوانهزنى با استفاده از فرمول (1) محاسبه شد كه در آن G درصد جوانهزنى، n تعداد نهايى بــرهاى جوانـهزده و N تعداد بذرهاى كشتشده است (Yo): $\mathrm{G}=(\mathrm{n} / \mathrm{N}) \times 100$ براى تعيين سرعت جوانهزنى از فرمول (T) استفاده شــ كـه در

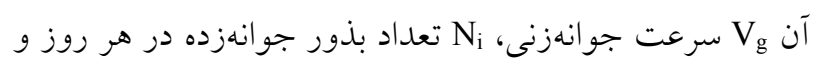
شماره روز است (Yo Di

$\mathrm{V}_{\mathrm{g}}=\Sigma \mathrm{N}_{\mathrm{i}} / \mathrm{D}_{\mathrm{i}}$

شاخص بنيه بذر براساس فرمول (r) از حاصـل ضـرب مجمـوع طول ريشه جֶه و ساقه جِه در درصد جوانهزنى بهدست آمد (Yo) كه در آن SV بنيه بذر، PL طول ساقه بحه، RL طول ريشهجهـه و GP

$\mathrm{SV}=(\mathrm{PL}+\mathrm{RL}) \times \mathrm{GP}$

با استفاده از فرمول (Y) شاخص تحمل به تنش بهدست آمد

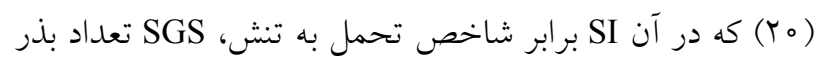
جوانهزده در شرايط تنش و SGA تعداد بذر جوانهزده در شرايط عادى است:

\section{$\mathrm{SI}=(\mathrm{SGS} / \mathrm{SGA}) \times 100$}

همجنين در پايان آزمايش نسبت به اندازه گيرى وزن تازه دانهال و ميانكين طول دانهال اقدام شد. دادههاى بهدستآمده با استفاده از نرمافزار آمارى SAS 9.1 تجزيه و تحليل شد و ميانخينها در سطح ه \% آزمون LSD با هم مقايسه شدند (YY).

نتايج و بحث نتـايج تجزيــه واريـانس صـفات مــورد ارزيـابى در آزمـايش
صورت مى يذيرد. بنابر اين برايمينخ بذر با مواد مختلـف مسىتوانـــ نشاء را براى مواجهه با شرايط تنش در زمين اصلى سازگار كند.

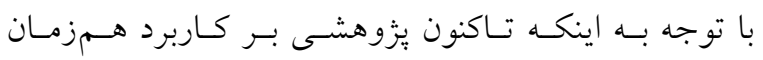

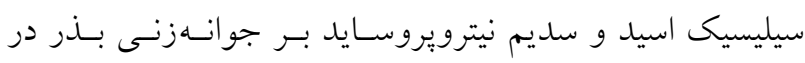
هيج گونه گياهى در كشور گزارش نشده است، هــدف از انجـام اين غيزوهش كاربرد سيليسيك اسيد و ســـيم نيتروبروسـايد بـر جوانهزنى بذر گوجهفرنخى رقم ايزابلا تحت شـرايط شـورى و بررسى صفات جوانهزنى و نيز رشد رويشى دانهال بود.

مواد و روش ها بهمنظور بررسى اثر خيساندن بـــر در محلـول سيليسـيك اسـيد و محلـول ســـيم نيترويروســايد (SNP) تهيــه شـــه از (SNA) شركت مرك آلمان، بر رفتار جوانهزنى بذر گوجسهفرنخى رقـم

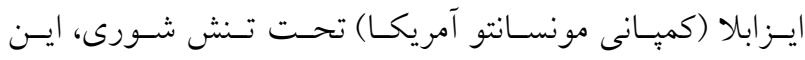
آزمايش بهصورت فاكتوريل بــا ه تكــرار در قالـب طـرح كـاملاً تصادفى در شرايط اتاق رشــ در دانشـعاه آزاد اسـلامى واحـــ جهرم انجام شد. در هر تكرار ه يترى ديش و در هر يترى ديش

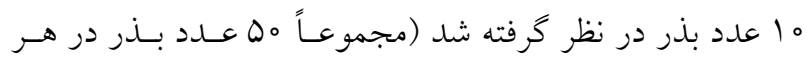

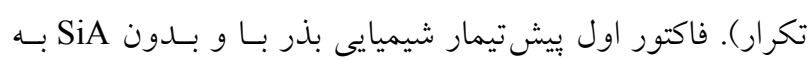
غلظت • r/D ميلى مولار، فاكتور دوم بيشتيمار شيميايى بذر با و بلدون محلول SNP به غلظت ه ه 1 ميكرومـولار و فـاكتور سـوم

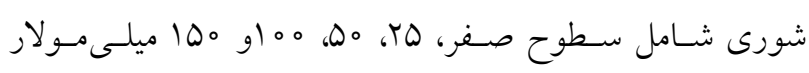

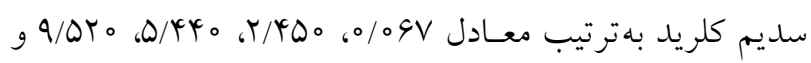

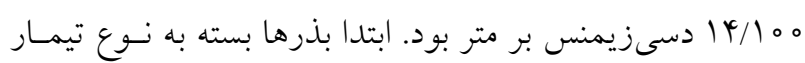
مورد آزمايش، بهمدت ها ساعت در آب مقطر يـا محلـول SiA

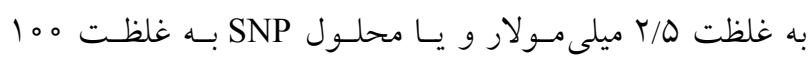
ميكرومولار خيسـانده و سـبس بلافاصـله در زيــر هـود جريـان هواى يكىطرفه تعداد ه ا بذر روى كاغذ واتمن درون هر يتـرى ديش قرار داده شد. قطر بترى ديشها 9 سانتى متـر بـود و همــه

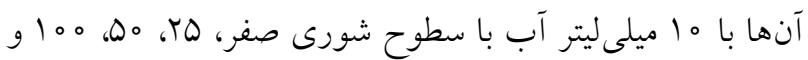

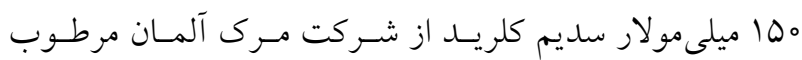
شدند. براى تهيه محلولهاى مذكور از آب مقطر بــراى شـورى 


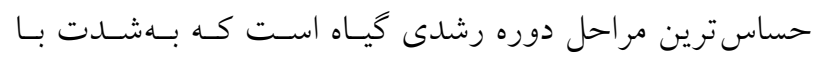

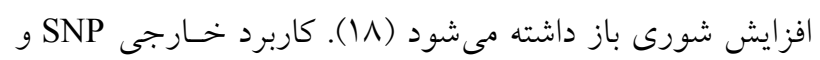
اثر تحريك كننده شديدى بر جوانهزنى بذر در شرايط تنش دائس

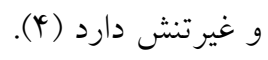

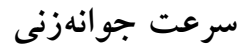

در مقايسه ميانخين برهم كنش سه فـاكتور SiA، SNP و شـورى بر سرعت جوانهزنى مشخص شد كه بيشترين سرعت جوانهزنى

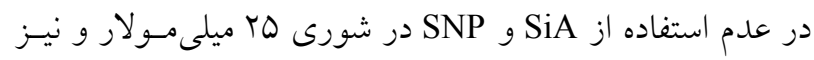

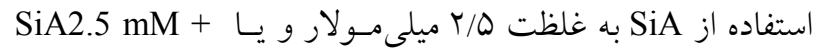
SNP100 بM

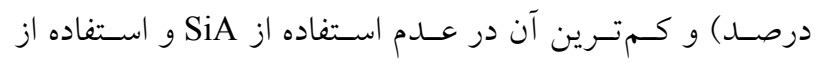
S و يا استفاده از SNP100 بM

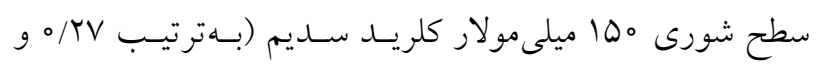

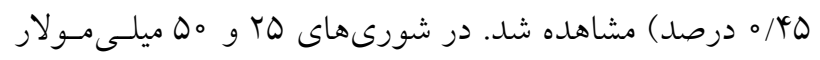

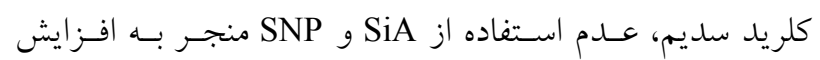
سرعت جو انهزنى در مقايسه با تيمارهـاى تركيبى SiA + SNP شد. در شورى ه 10 ميلى مولار كلريد سديم، استفاده از

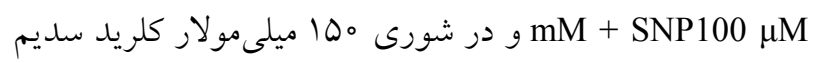
استفاده از SiA2.5 mM بدون استفاده از SNP منجر به افـزايش

$$
\text { سرعت جوانهزنى شد (جدول Y). }
$$

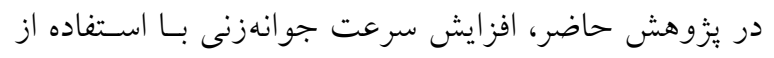

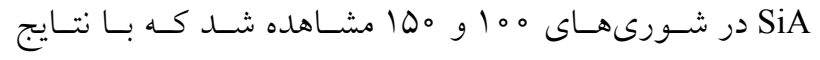

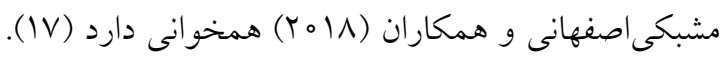

\section{شاخص بنيه بذر}

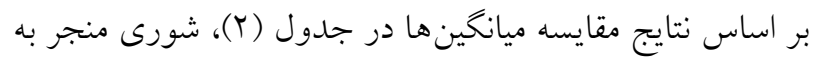
كاهش معنى دار شاخص بنيه بذر شد و در ايسن رابطـه بيشـترين

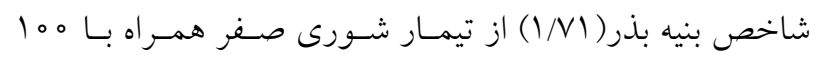

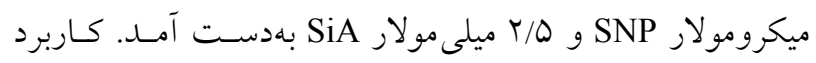
SNP

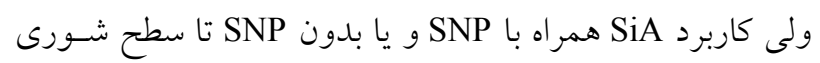

جو انهزنى بذر كوجهفرنخى در سطوح مختلف شورى در جدول

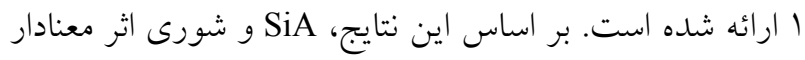

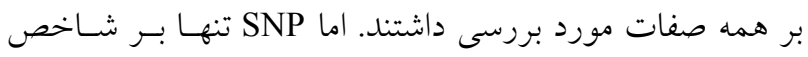

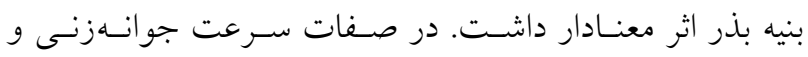

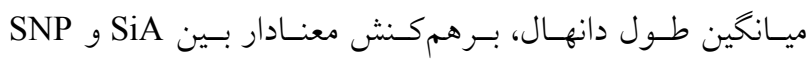

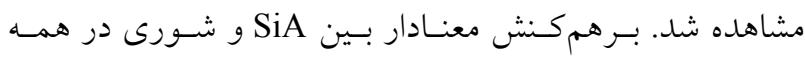
صفات بهجز درصد جوانهزنى و شاخص تحمل به تنش وجـود داشت. برهم كنش بين SNP و شورى در همه صـفات معنسى دار

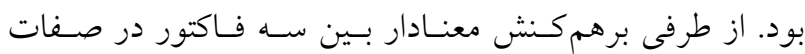
سرعت جوانهزنى، شاخص بنيه بذر و وزن تازه دانهال مشـاهده

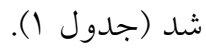
درصد جوانهزنى بذر مقايسه ميانخين اثر اصلى SiA بر درصد جوانهزئى بدر بذر نشان داد

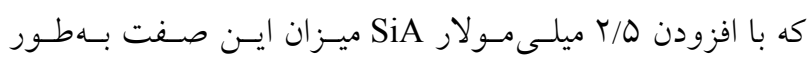

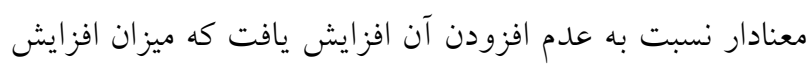
( 9/4 درصد بود (شكل (1).

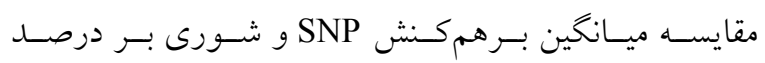

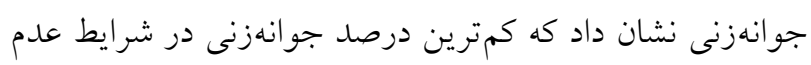

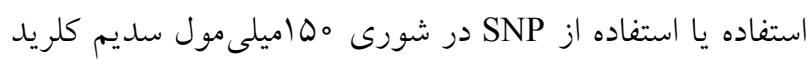
(بهترتيب 99 و 94 درصد) مشاهده شد. بين بقيه تيمارها تفاوت

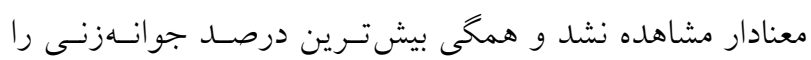

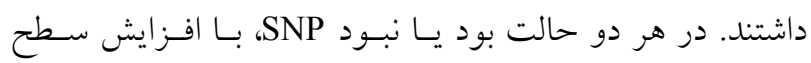

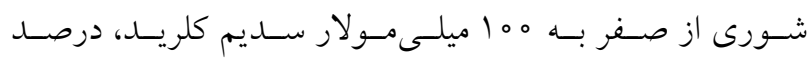

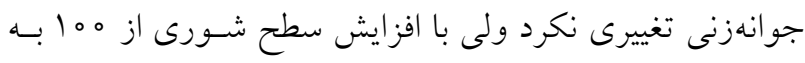

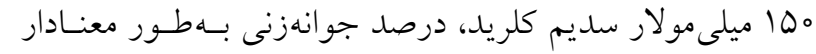
كاهش يافت (حدود مه درصد). در اين رابطه افزوون SNP در

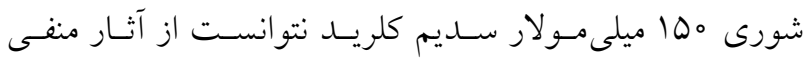

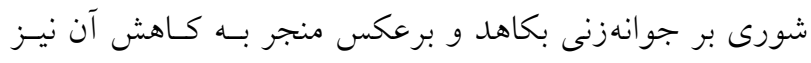

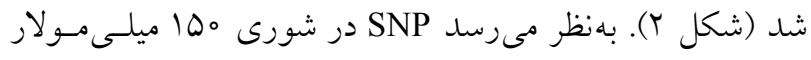

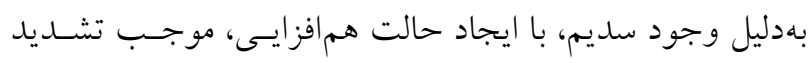

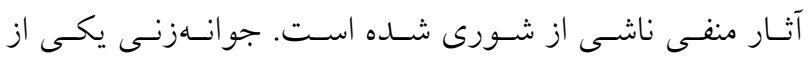




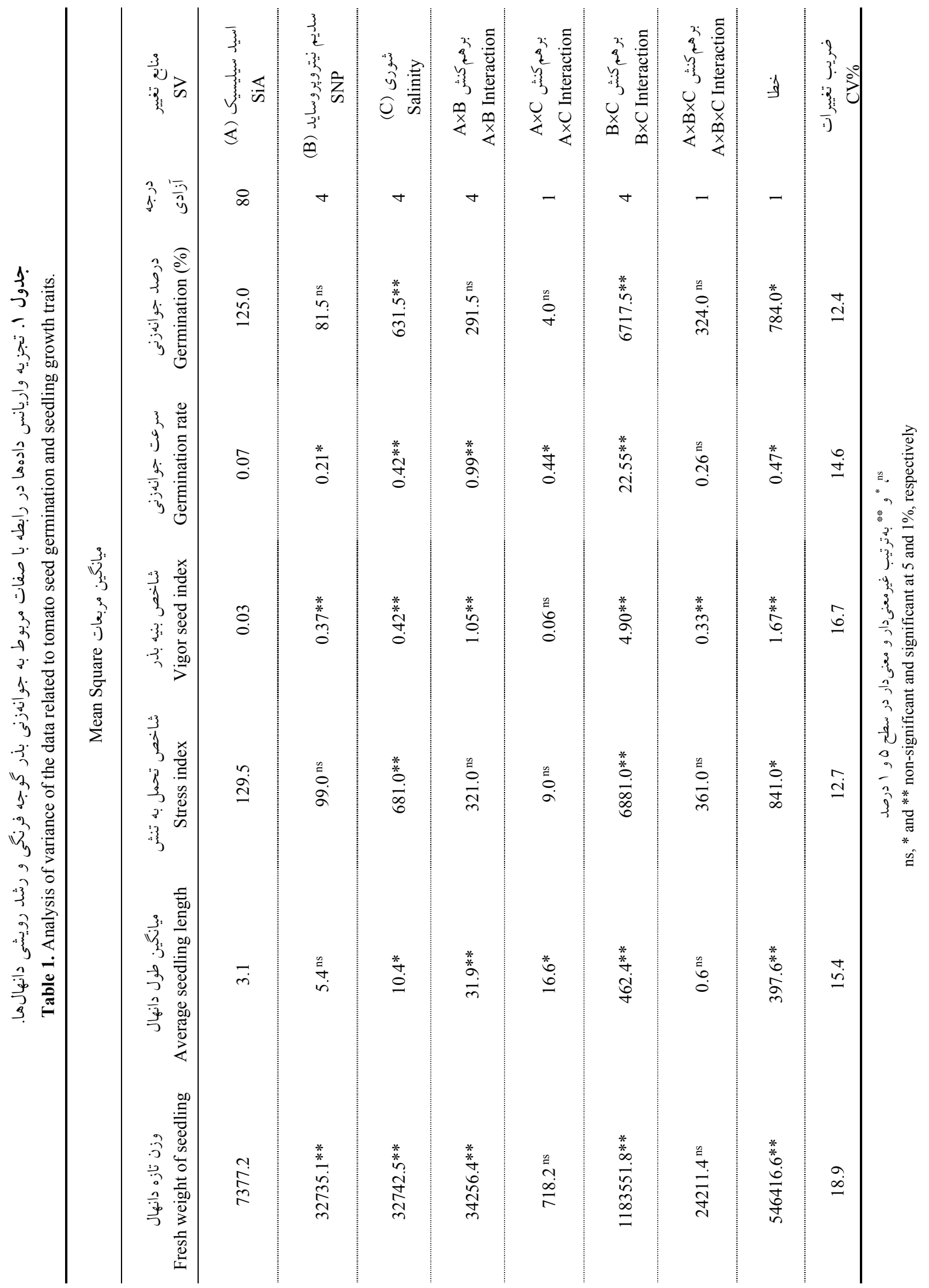




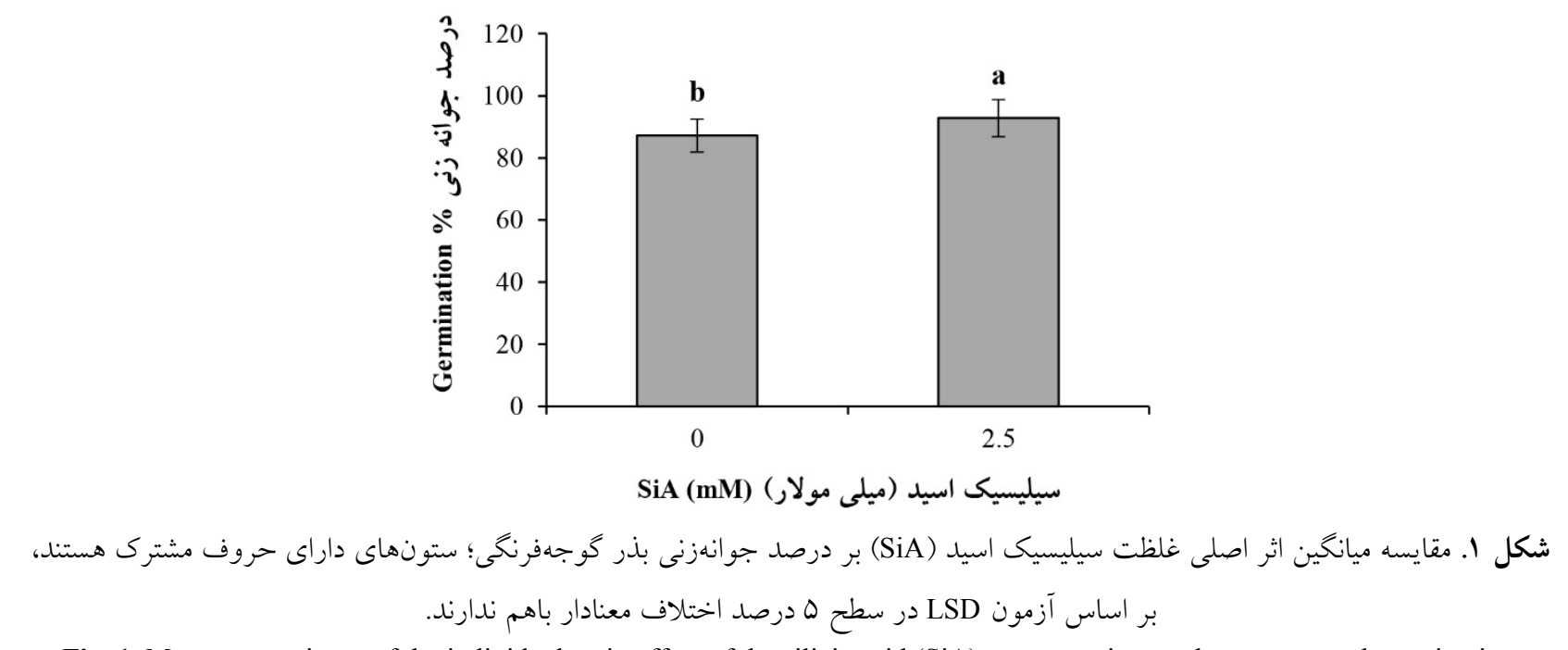

Fig. 1. Mean comparisons of the individual main effect of the silicic acid (SiA) concentration on the tomato seed germination percentage; Columns with the same letters do not represent a significant difference at the $5 \%$ level of the LSD test.

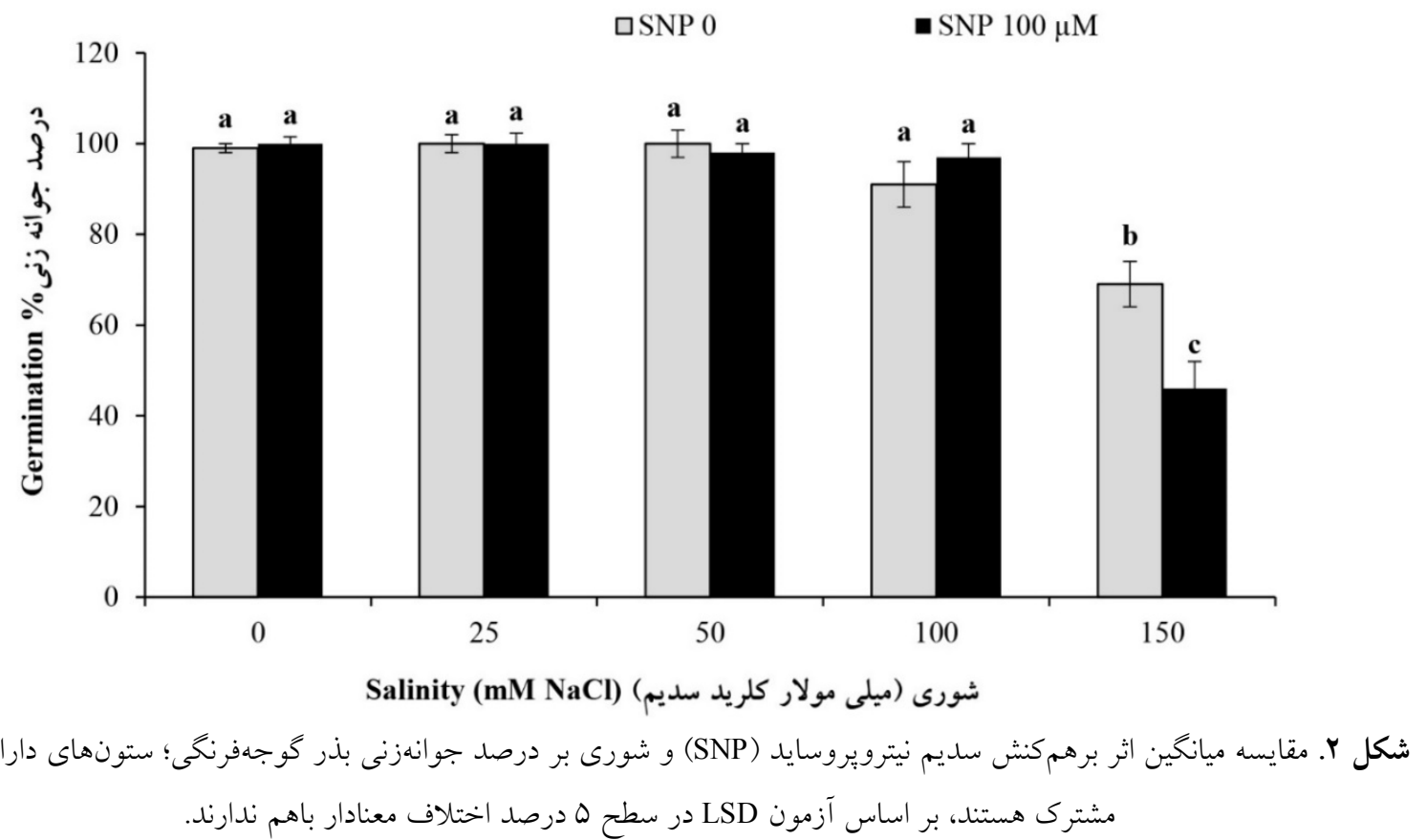

Fig. 2. Mean comparisons of the interaction effect of the sodium nitroprusside (SNP) concentration on the tomato seed germination percentage; Columns with the same letters do not represent a significant difference at the $5 \%$ level of the LSD test.

متفاوت است، بنابراين انتخاب گياه براى كشت در زمينهاى شور، بايد از جنبههاى مختلف بررسى شود (Y (I). اخرجهه تنش شورى در تمام مراحل رشد كياه ممكن است رخ دهد، اما با توجه به اينكه شرايط استقرار اوليه كياه، در عملكرد نهايى تأثير زيادى دارد، بنابراين تنش شورى در مرحله دانهالى، مىتواند براى گياه بسيار مضر باشد (Yl). بررسى اثر سرعت و درصد

$$
\begin{aligned}
& \text { o م الميلى مولار سديم كلريد بهطور معنادار باعث حفظ بنيه بذر } \\
& \text { شد (جدول Y). در يزّوهش انجامشده در مورد بذر گوجهفرنكى } \\
& \text { رقم PS نيز كاربرد نانوذرات سيليكون توانست شاخص بنيه بذر } \\
& \text { را در شرايط تنش شورى افزايش دهد (IV). } \\
& \text { شورى خاى يكى از مهمترين جالشها در كشاورزى } \\
& \text { محسوب مىشود و دامنه تحمل گياهان نسبت به شورى }
\end{aligned}
$$


جدول r. مقايسه ميانكين اثر برهم كنش سه گانه سيليسيك اسيد (SiA)، سديم نيترويروسايد (SNP) و شورى بر سرعت جوانهزنى بذر كوجهفرنكى.

Table 2. Mean comparisons of the triple interaction effect of silicic acid (SiA), sodium nitroprusside (SNP) and salinity on the tomato seed germination rate.

\begin{tabular}{|c|c|c|c|c|c|}
\hline $\begin{array}{l}\text { وزن تازه دانهال (ميلى گرم) } \\
\text { Fresh weight of seedling } \\
\text { (mg) }\end{array}$ & شاخص بنيه بذر & سرعت جوانهزنى & & $\begin{aligned} & \text { صفت } \\
\times & \mathrm{Si} \times \text { Salinity }\end{aligned}$ & \\
\hline $355^{\mathrm{gh}}$ & $1.54^{\mathrm{ab}}$ & $2.52^{\mathrm{bc}}$ & SNP $0 \mu \mathrm{M}$ & \multirow{2}{*}{$\mathrm{SiA} 0 \mathrm{mM}$} & \multirow{4}{*}{$\begin{array}{l}\text { Salinity } \\
0 \text { شورى }\end{array}$} \\
\hline $454 \mathrm{fg}$ & $1.56^{\mathrm{ab}}$ & $2.82^{\mathrm{b}}$ & SNP $100 \mu \mathrm{M}$ & & \\
\hline $479 \mathrm{f}$ & $1.70^{\mathrm{a}}$ & $3.30^{\mathrm{a}}$ & SNP $0 \mu \mathrm{M}$ & \multirow{2}{*}{$\mathrm{SiA} 2.5 \mathrm{mM}$} & \\
\hline $457 \mathrm{fg}$ & $1.71^{\mathrm{a}}$ & $3.33^{\mathrm{a}}$ & SNP $100 \mu \mathrm{M}$ & & \\
\hline $596 \mathrm{de}$ & $1.44^{\mathrm{b}}$ & $3.16^{\mathrm{a}}$ & SNP $0 \mu \mathrm{M}$ & \multirow{2}{*}{$\mathrm{SiA} 0 \mathrm{mM}$} & \multirow{4}{*}{$\begin{array}{l}\text { Salinity } \\
25 \text { شورى } \\
\text { mM }\end{array}$} \\
\hline $711 \mathrm{bc}$ & $1.39^{\mathrm{bc}}$ & $2.40^{\mathrm{cd}}$ & SNP $100 \mu \mathrm{M}$ & & \\
\hline $784 \mathrm{ab}$ & $1.51^{\mathrm{ab}}$ & $2.35^{\mathrm{cd}}$ & $\mathrm{SNP} 0 \mu \mathrm{M}$ & \multirow{2}{*}{$\mathrm{SiA} 2.5 \mathrm{mM}$} & \\
\hline $829 a$ & $0.46^{\mathrm{fg}}$ & $2.40^{\mathrm{cd}}$ & SNP $100 \mu \mathrm{M}$ & & \\
\hline $630 \mathrm{~cd}$ & $1.14^{\mathrm{d}}$ & $2.40^{\mathrm{cd}}$ & $\mathrm{SNP} 0 \mu \mathrm{M}$ & \multirow{2}{*}{$\mathrm{SiA} 0 \mathrm{mM}$} & \multirow{4}{*}{$\begin{array}{l}\text { Salinity } \\
50 \text { شورى } \\
\text { mM }\end{array}$} \\
\hline $417 \mathrm{fgh}$ & $0.69^{\mathrm{e}}$ & $1.90^{\mathrm{e}}$ & SNP $100 \mu \mathrm{M}$ & & \\
\hline $732 a b c$ & $1.50^{\mathrm{ab}}$ & $2.10^{\mathrm{de}}$ & SNP $0 \mu \mathrm{M}$ & \multirow{2}{*}{$\mathrm{SiA} 2.5 \mathrm{mM}$} & \\
\hline $748 \mathrm{ab}$ & $1.48^{\mathrm{b}}$ & $1.83^{\mathrm{ef}}$ & SNP $100 \mu \mathrm{M}$ & & \\
\hline $165 \mathrm{i}$ & $0.41^{\text {fgh }}$ & $0.78^{\mathrm{gh}}$ & SNP $0 \mu \mathrm{M}$ & \multirow{2}{*}{$\mathrm{SiA} 0 \mathrm{mM}$} & \multirow{4}{*}{$\begin{array}{l}\text { Salinity } \\
100 \text { شورى } \\
\text { mM }\end{array}$} \\
\hline $339 \mathrm{~h}$ & $0.62^{\mathrm{ef}}$ & $0.79^{\mathrm{gh}}$ & SNP $100 \mu \mathrm{M}$ & & \\
\hline $465 f$ & $1.19^{\mathrm{cd}}$ & $1.05^{\mathrm{g}}$ & SNP $0 \mu \mathrm{M}$ & \multirow{2}{*}{$\mathrm{SiA} 2.5 \mathrm{mM}$} & \\
\hline $520 \mathrm{ef}$ & $1.36^{\mathrm{bcd}}$ & $1.52^{\mathrm{f}}$ & SNP $100 \mu \mathrm{M}$ & & \\
\hline $96 \mathrm{ij}$ & $0.20^{\mathrm{hi}}$ & $0.49^{\mathrm{hi}}$ & SNP $0 \mu \mathrm{M}$ & \multirow{2}{*}{$\mathrm{SiA} 0 \mathrm{mM}$} & \multirow{4}{*}{$\begin{array}{l}\text { Salinity } \\
150 \text { سورى } \\
\text { mM }\end{array}$} \\
\hline $49 \mathrm{j}$ & $0.15^{\mathrm{i}}$ & $0.27^{\mathrm{i}}$ & SNP $100 \mu \mathrm{M}$ & & \\
\hline $92 \mathrm{ij}$ & $0.37^{\mathrm{gh}}$ & $0.58^{\mathrm{hi}}$ & SNP $0 \mu \mathrm{M}$ & \multirow{2}{*}{$\mathrm{SiA} 2.5 \mathrm{mM}$} & \\
\hline $182 \mathrm{i}$ & $0.44^{\mathrm{fg}}$ & $0.45^{\mathrm{i}}$ & SNP $100 \mu \mathrm{M}$ & & \\
\hline
\end{tabular}

در هر ستون ميانگينهاى داراى حروف مشترك، بر اساس آزمون LSD در سطح ه درصد اختلاف معنادار باهم ندارند.

Means in each columns with the same letters do not represent a significant difference at the 5\% level of the LSD test.

\section{وزن تازه دانهال}

مقايسه ميانكين برهم كنش سه فاكتور بر وزن تازه گياه مشـخص

كرد كه بيشترين وزن تازه دانهـال در تيمـار استفاده از SiA2.5

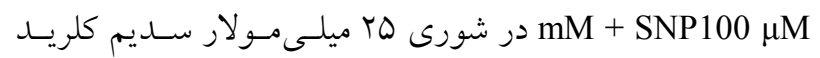
(

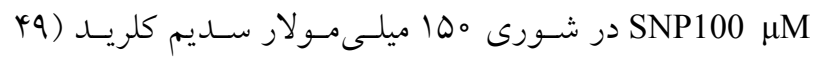
ميلى گـرم) مشــاهده شـــ. در همـه سـطوح شـورى اسـتفاده از منجر به افزايش وزن تازه دانهـال SiA2.5 mM + SNP100 بM در مقايسه با بقيه تيمارهاى تركيبى SiA + SNP شد (جدول r). در يك يززوهش، استفاده از ا ميلى مـولار SiA در شــايط تسنش شورى ناشى از كلريد كلسيم باعث افزايش وزن بـرى در گيـاه

$$
\begin{aligned}
& \text { جوانهزنى در بسيارى از گياهان نشان داده است كه تنش شـورى در } \\
& \text { مرحله جوانهزنـى يـك آزمـون قابـل اطمينـان، در ارزيـابى تحمـل } \\
& \text { بسيارى از گونه ها است زيرا اين مرحله به شدت تحت تـأثير ميـزان } \\
& \text { املاح قـرار مسى گيــرد و شـورى باعـث كـاهش درصــ و سـرعت } \\
& \text { جوانهزنى مى شود (Y). نمـك موجـب كـاهش جـذب آب توسط } \\
& \text { بذور و افزايش جذب يونها تـا حــــ مسـموميت مسى شـود، بـــين } \\
& \text { ترتيب جوانهزنى بذر و ظهور دانهال كاهش مىيابد (Y). بـر اسـاس } \\
& \text { نتايج يزوهش حاضر، با افزايش شورى، درصد جوانهزنس، سـرعت } \\
& \text { جوانه زنى و شاخص بنيه بذر كاهش يافت درحسالى كـه اسـتفاده از } \\
& \text { تيمارهـاى حـاوى سيليسـيك اسـيد، بارامترهـاى جوانسهزنسى رادر } \\
& \text { مقايسه با شاهد بهطور معنى دارى افزايش داد. }
\end{aligned}
$$




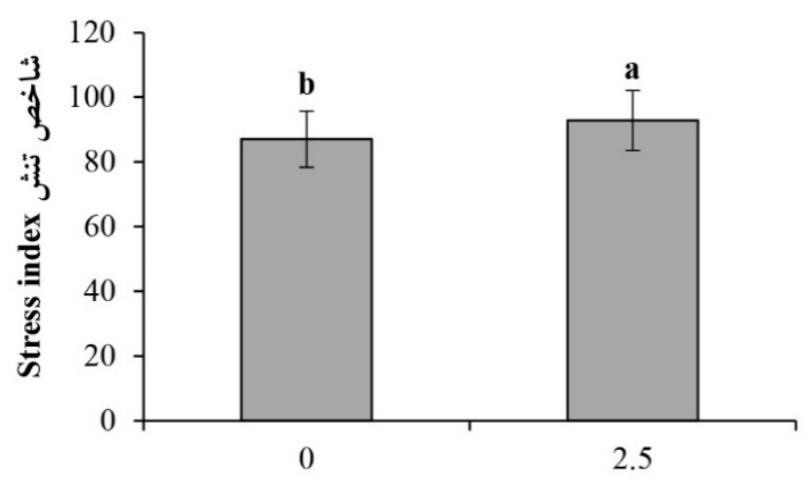

SiA (mM) سيليسيك اسيد (ميلى مولار)

شكل r. مقايسه ميانگين اثر سيليسيك اسيد (SiA) بر شاخص تحمل به تنش دانهال گوجهفرنخى؛ ستونهاى داراى حروف مشترك هستند، بر

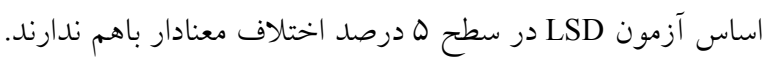

Fig. 3. Mean comparisons of the effect of silicic acid (SiA) on the stress index of tomato seedlings; Columns with the same letters do not represent a significant difference at the $5 \%$ level of the LSD test.

شر ايط تنش در مقايسه بـا شـرايط طبيعى گيـاه اسـت (م). در

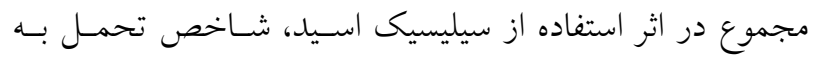
تنش افزايش معنادار يافت. در يك ئزوهش، كاربرد ا ميلى مولار

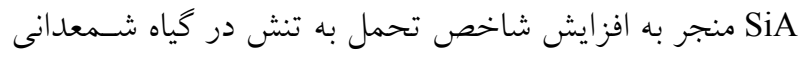

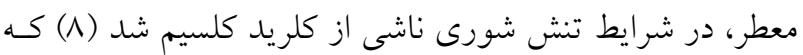
با نتايج يزوهش حاضر همخوانى دارد.

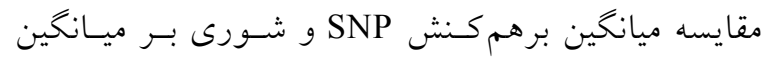

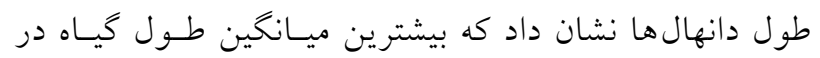

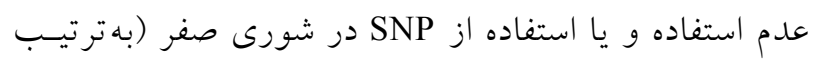

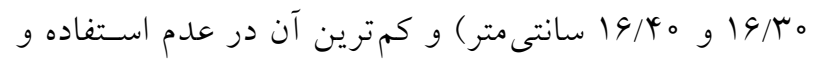

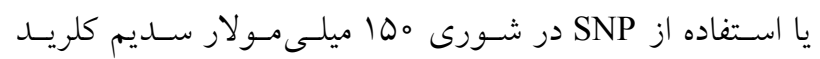

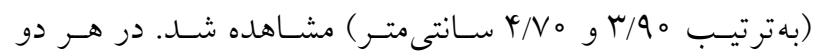

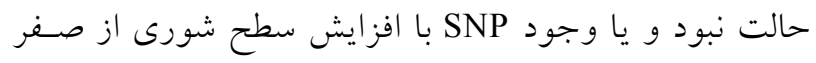

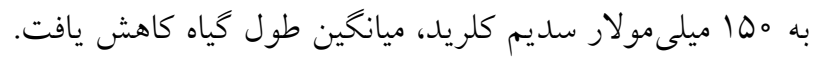

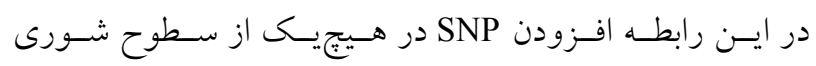
نتوانست بهطور معنادار آثار منفى شورى بر ميانخين طـول كيــاه را بكاهد (شكل ه). مقايسه ميانخين برهم كنش SiA و شورى بـر ميـانخين طـول

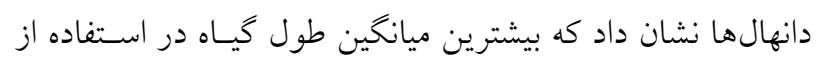
SiA

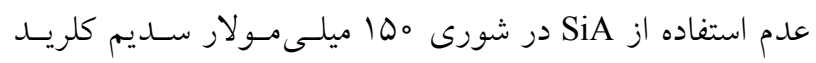

شمعدانى معطر شد (N). افزايش وزن تازه گياه در شرايط تسنش شورى، با استفاده از كاربرد سيليسيم در بسيارى از كَياهان مانند

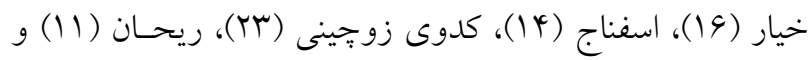

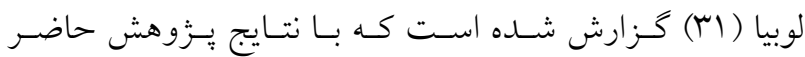
همخوانى دارد. شاخص تحمل به تنش مقايسه ميانخين اثر اصلى SiA بر شاخص تحمله نتصل به تنش نشـان

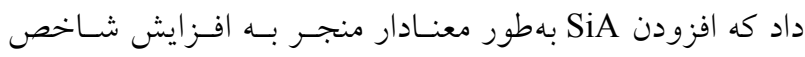
تحمل به تنش شد (شكل r).

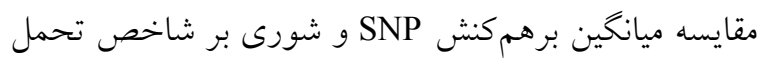

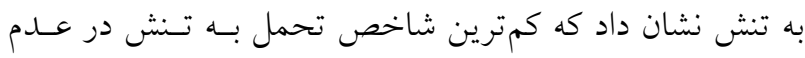

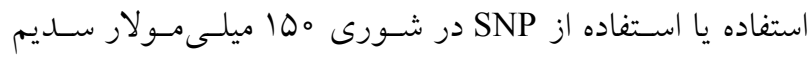
كلريد (بهترتيب 99 و 94) مشاهده شد. بين بقيه تيمارها تفاوت

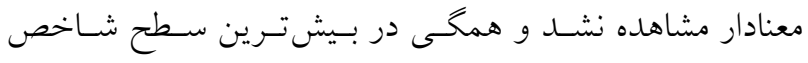

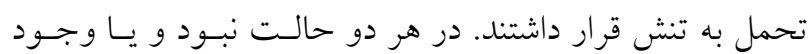

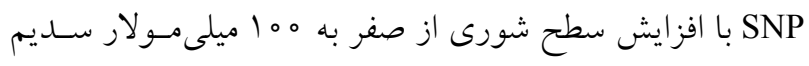

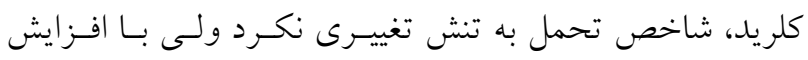

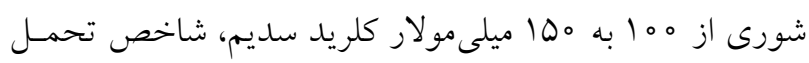

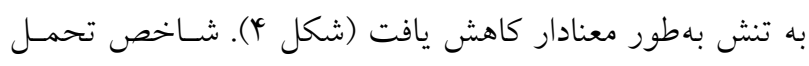

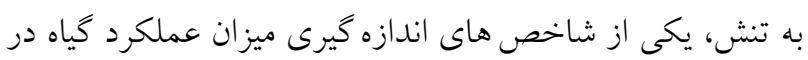




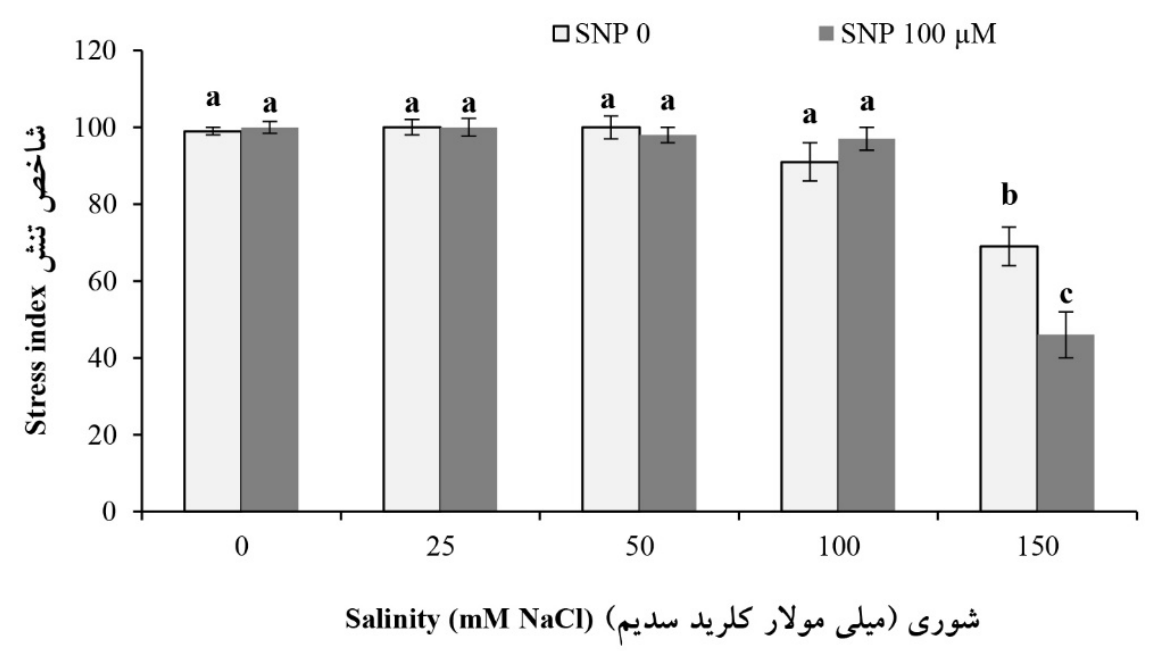

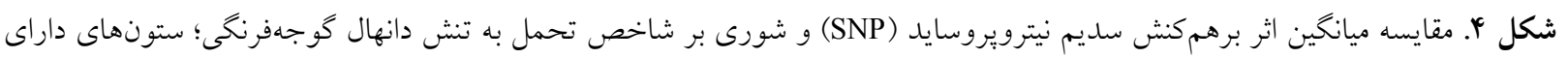

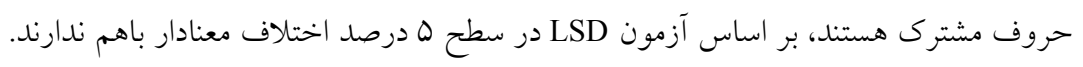

Fig. 4. Mean comparisons of the interaction effect of sodium nitroprusside (SNP) and salinity on the stress index of tomato seedlings; Columns with the same letters do not represent a significant difference at the 5\% level of the LSD test.

يزوهش هاى بيشين در كياهان مختلف همخوانى دارد. وانـخ و همكاران (TV) نشان دادند كه سيليسيليك اسيد در غلظتهاى 1

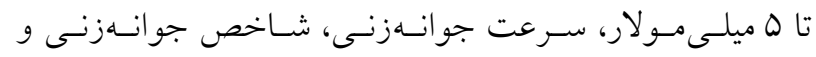
شاخص بنيه بذر در كياه Momordica charantia را در شـرايط

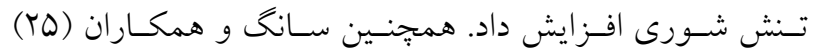

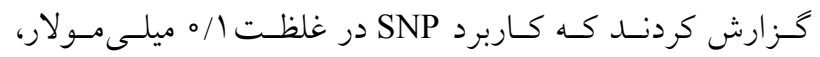
جوانهزنى . Salsola soda L را در تنش شورى بهبود بخشيد. در يزوهشى ديخر، كاربرد خارجى SiA در شرايط تنش بى بكربنـات

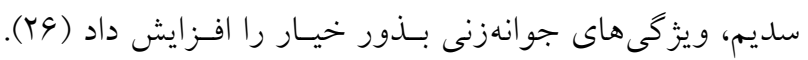

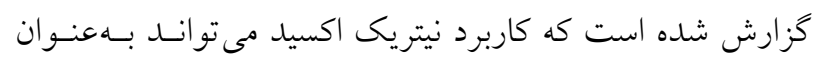

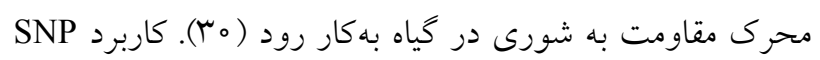

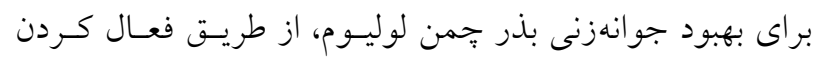

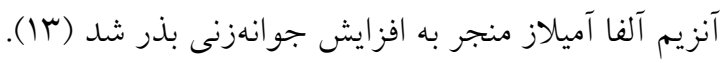

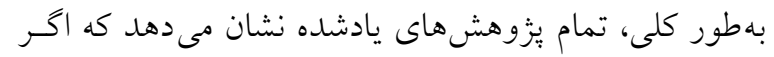

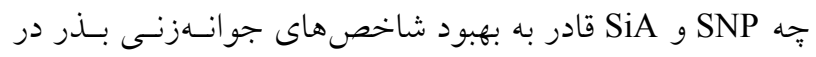
شرايط شورى هستند ولى مكانيسم اساسى بهمنظور درى بهتر

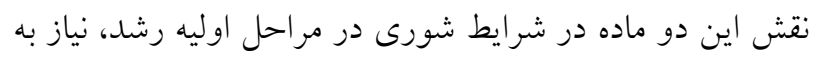
بررسى هاى بيشتر دارد (YT).
( T/N سانتىمتر ) مشاهده شد. در هر دو حالت نبود و يـا وجـود

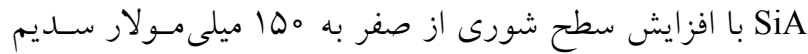
كلريد، ميانگين طول كياه كاهش يافـت. در ايـن رابطــه افـزودن

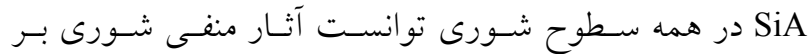
ميانكين طول كياه را تعديل كند (شكل 9). حسنوند و همكاران

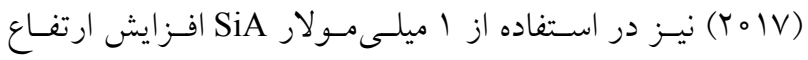
كياهان شمعدانى معطر را در شرايط تسنش شـورى ناشسى از 10

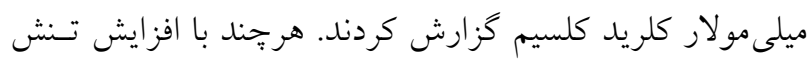

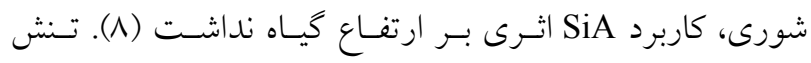

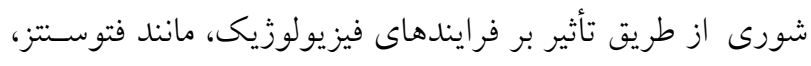

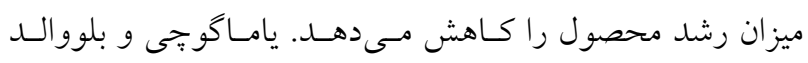
(Y०00)

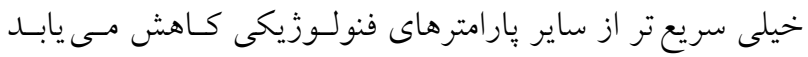

براساس نتايج يزوهش حاضر، درصـد جو انسهزنسى، سـرعت

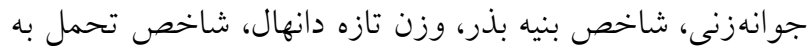
تنش و طول كياه در اثر تنش شورى كاهش يافت. بـا ايـن حـال

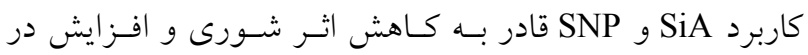

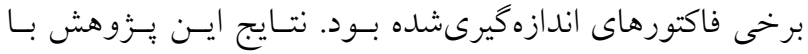




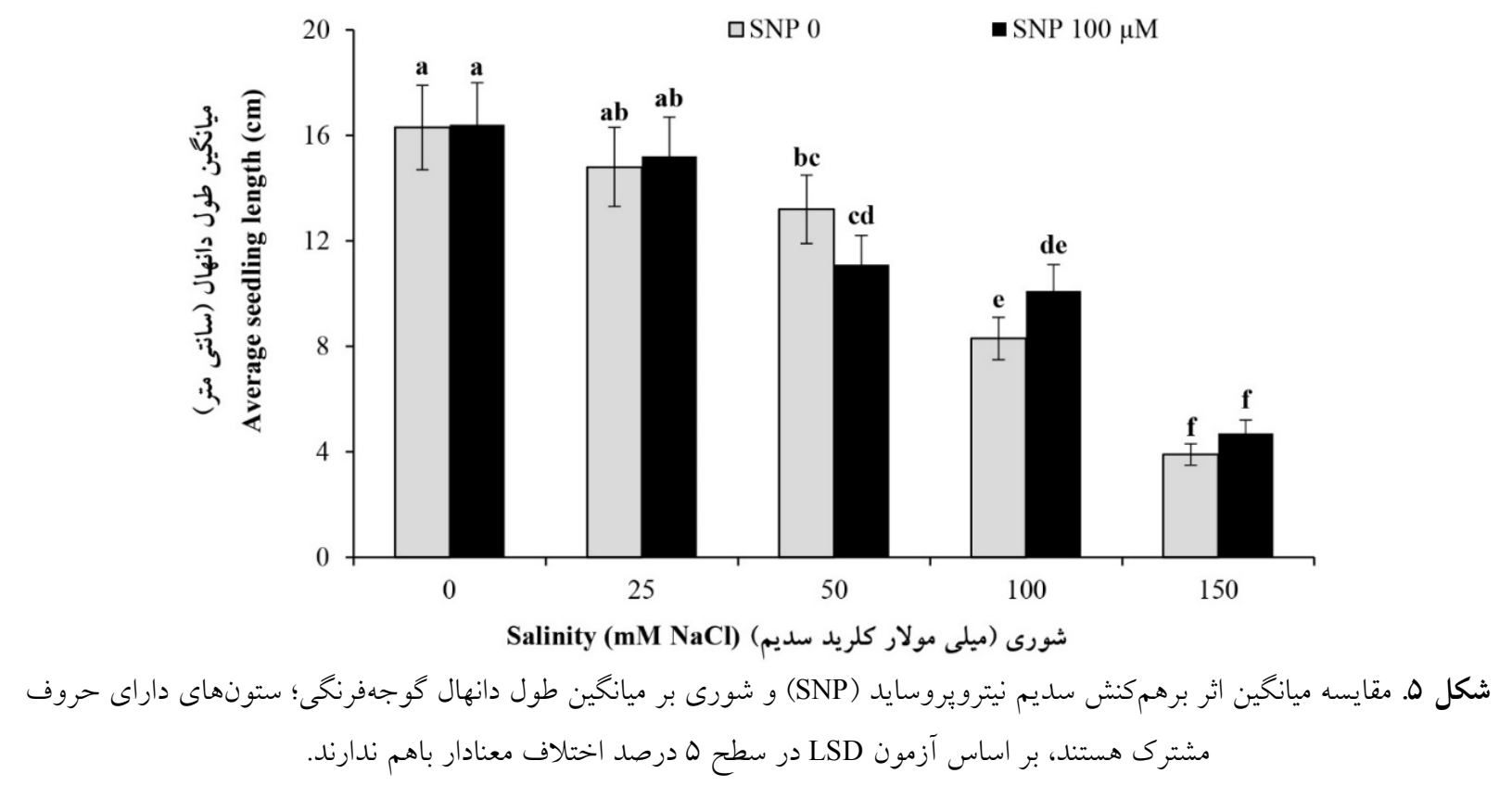

Fig. 5. Mean comparisons of the interaction effect of sodium nitroprusside (SNP) and salinity on the average tomato seedlings length; Columns with the same letters do not represent a significant difference at the $5 \%$ level of the LSD test.

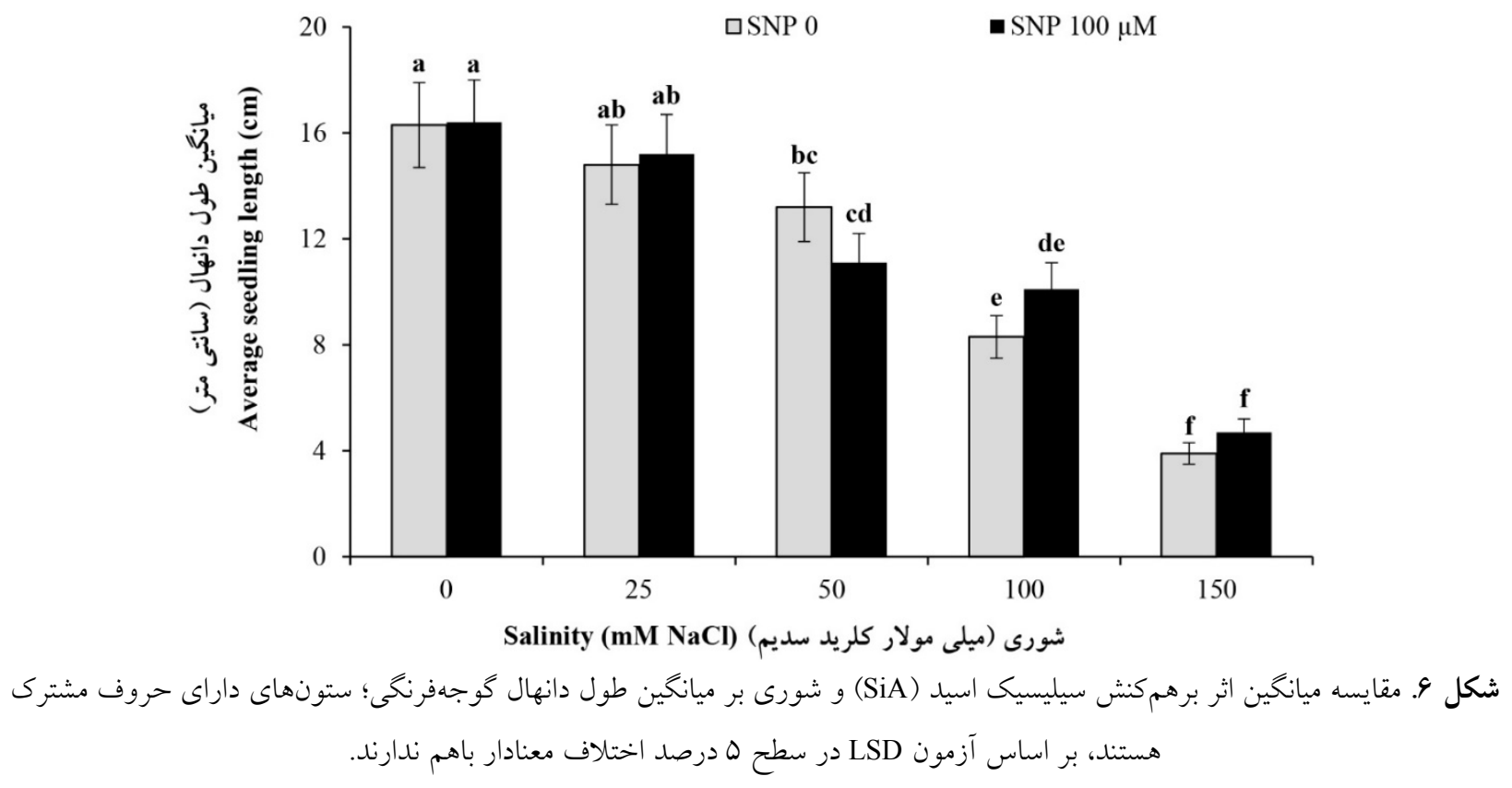

Fig. 6. Mean comparisons of the interaction effect of silicic acid (SiA) and salinity on the average tomato seedlings length; Columns with the same letters do not represent a significant difference at the 5\% level of the LSD test.

تأثير معنادار در تعديل آثار شورى بر شاخصهـاى SiA و SNP<smiles>[As][As]=[As]</smiles>

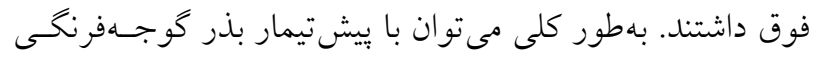

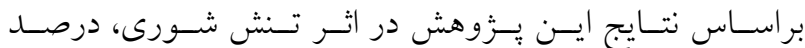

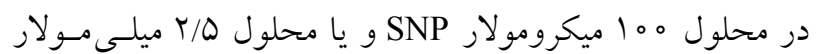

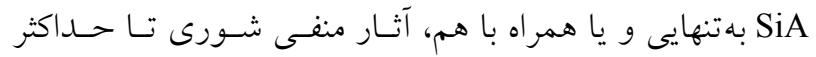

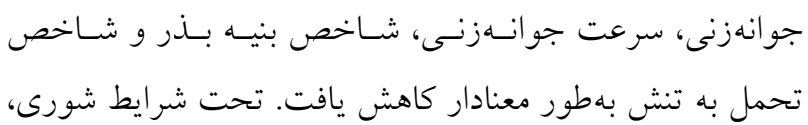




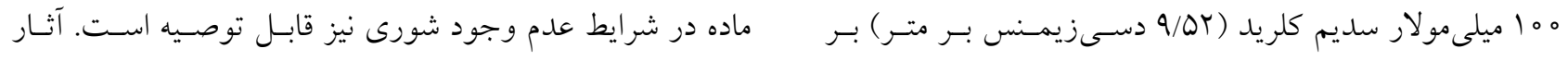

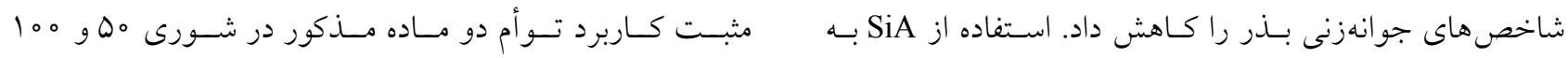

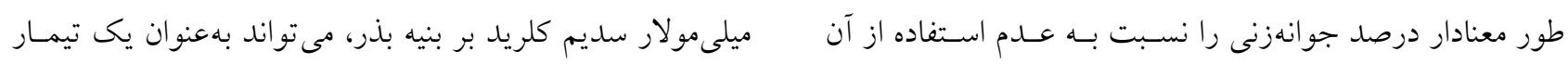

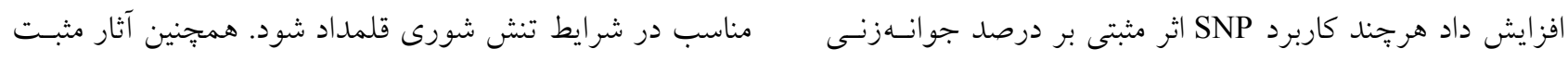

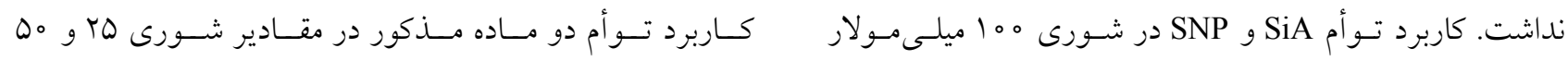

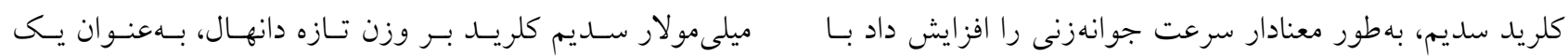

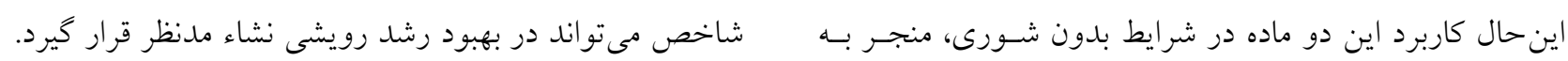

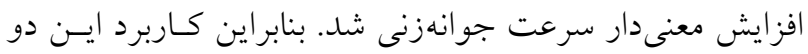

\section{منابع مورد استفاده}

1. Arasimowicz, M., Floryszak-Wieczorek, J., 2007. Nitric oxide as a bioactive signaling molecule in plant stress responses. Plant Science 172: 876-887. https://doi.org/10.1016/j.plantsci. 2007.02.005.

2. Ashraf, M., Foolad, M.R., 2005. Pre-sowing seed treatment a shotgun approach to improve germination, plant growth and crop yield under saline and non saline conditions. Advances in Agronomy 88: 223-271.

3. Avestan, S., Lotfalim N., 2016. Effects of nano silicon $\left(\mathrm{SiO}_{2}\right)$ application on in vitro proliferation of Gala apple cultivar. Iranian Journal of Horticultural Science 46(4): 669-675.

4. Beligni, M.V., Lamattina, L., 2000. Nitric oxide stimulates seed germination and de-etiulation, and inhibits hypocotyl elongation, light-inducible responses in plants. Planta 210(2): 215-221. https://doi.org/10.1007/PL00008128. 5. Bybordi, A., 2014. Interactive effects of silicon and potassium nitrate in improving salt tolerance of wheat. Integrative Journal of Agriculture 13: 1889-1899. (In Persian)

6. Faalian, A., Ansari, H., Kafi, M., Alizadeh, A., Moghaddasi, M., 2015. Effect of salinity and drought stresses on economical aspect of hydroponic production of greenhouse tomato. Journal of Water Research in Agriculture 29(3): 317-330. (In Persian)

7. Haghighi, M., Afifipour, Z., Mozafarian, M., 2012. The alleviation effect of silicon on seed germination and seedling growth of tomato under salinity stress. Vegetable Crops Research Bulletin 76: 119-126. (In Persian)

8. Hassanvand, F., RezaeiNejad, A. Feizian, M., 2017. Effect of silicic acid on some morphological and physiological characteristics of Pelargonium graveolens $\mathrm{L}$. under $\mathrm{CaCl}_{2}$ salinity stress. Plant Research Journal 30(2): 309-317. (In Persian) 9. Hubbard, M., Germida, J., Vujanovic, V., 2012. Fungal endophytes improve wheat seed germination under heat and drought stress. Botany 90(2): 137-149.

10. Gupta, B., Huang, B., 2014. Mechanism of salinity tolerance in plants: physiological, biochemical, and molecular characterization. International Journal of Genomics 2014: 701596. https://doi.org/10.1155/ 2014/701596.

11. Kalteh, M., Alipour, Z., Ashraf, S., Marashi Aliabadi, M., Falah Nosratabadi, A., 2014. Effect of silica nanoparticles on Basil (Ocimum basilicum) under salinity stress. Journal of Chemistry Health Risks. 4(3): 49-55. (In Persian)

12. Khan, M.A., Gulzar, S., 2003. Germination responses of Sporobolus ioclados: A saline desert grass. Journal of Arid Environment 55: 453-464.

13. Liu J.X., Wang, X., Le, R.X., 2007. Effect of exogenous nitric oxide donor SNP on seed germination and seedling growth of Lolioum multiflorum. Chinese Journal of Ecology 3: 543-546.

14. Mateos-Naranjo, E., L. Andrade's-Moreno, L., Davy, A.J., 2013. Silicon alleviates deleterious effects of high salinity on the halophytic grass Spartina densiflora. Plant Physiology and Biochemistry 63: 115-121.

15. Malakuti, M.J., Keshavarz, P., Saadat, S., Kholdbarin, B., 2003. Plant Nutrition Under Saline Condition. Sana Publication 233p. (In Persian)

16. Mohaghegh, P., Shirvani, M., Ghasemi, S., 2010. Effect of silicium on growth and yield of two cucumber cultivars in hydroponic system. Journal of Science and Technology of Greenhouse Cultivations 1(1): 35-39. (In Persian)

17. Moshabaki Isfahani, F., Tahmoorespour, A., Hoodaji, M., Ataabadi, M., Mohamadi. A., 2018. Effect of bacterial inoculation, bacterial exopolysaccharide and nano $\mathrm{SiO}_{2}$ particles on seed germination of Solanum lycopersicum under salinity stress. Soil Biology Journal 6(1): 43-55. (In Persian)

18. Parvaiz, A., Satyawati, S., 2008. Salt stress and phyto-biochemical responses of plants - a review. Plant Soil and Environment 54: 89-99. 
19. Pouresmael, M., Valiani, E., 2011. Genetic diversity evaluation of salinity tolerance in Kabuli chickpea core collection of National Plant Gene Bank of Iran at germination stage. Journal of Applied Biology 24(1): 13-31.

20. Rahimi, A., Shamsodin, M.S., Etemadi, F., 2011. Effects of salt stress on germination, growth and ion contents of Cumin (Nigella sativa L.). Arid Biom Scientific and Research Journal 1(2): 20-30.

21. Rauf, M., Afzal, M., Munir, M., 2007. Performance of wheat genotypes under osmotic stress at germination and early seedling growth stage. African Journal of Biotechnology 6: 971-975.

22. Rizwan, M., Meunier, J.D., Miche, H., Keller, C., 2012. Effect of silicon on reducing cadmium toxicity in durum wheat (Triticum turgidum L. cv. Claudio W.) grown in a soil with aged contamination. Journal of Hazard Material 209: 210: 326-334.

23. Savvas, D., Giotis, D., Chatzieustratiou, E., Bakea, M., Patakioutas, G., 2009. Silicon supply in soilless cultivations of zucchini alleviates stress induced by salinity and powdery mildew infections. Environmental Experimental Botany 65: 11-17.

24. Soltani, A., Torabi, B., 2014. Designing and Analysis of Agricultural Experiments, With SAS Programs. JihadDaneshgahi Mashhad Press $431 \mathrm{p}$.

25. Song, J., Shi, G., Xing, S., Chen, M., Wang, B., 2009. Effects of nitric oxide and nitrogen on seedling emergence, ion accumulation, and seedling growth under salinity in the euhalophyte Suaeda salsa. Journal of Plant Nutrition and Soil Science 172(4): 544-549.

26. Sun, Y., Luo, W., Zhang, W., Ziumei, X., 2010. Effects of exogenous silicon on germination characteristics of cucumber seeds under $\mathrm{NaHCO}_{3}$ stress. International Conference on Challenges in Environmental Science and Computer Engineering's Editorial Policy 1: 471-474. http://doi.org/10.1109/CESCE.2010.14.

27. Wang, X.D., Ou-yang, C., Fan, Z.R., Gao, S., Chen, F., Tang, F., 2010. Effects of exogenous silicon on seed germination and antioxidant enzyme activities of Momordica charantia under salt stress. Journal of Animal and Plant Science 6(3): 700-708.

28. Yamaguchi, T., Blumwald, E., 2005. Developing salt-tolerant crop plants: Challenges and opportunities. Trends in Plant Science 12: 615-620.

29. Zheng, C., Jiang, D., Liu, F., Dai, T., Liu, W., Jing, Q., Cao, W., 2009. Exogenous nitric oxide improves seed germination in wheat against mitochondrial oxidative damage induced by high salinity. Environmenal and Experimental Botany 67(1): 222-227.http://doi.org/10.1016/j.envexpbot. 2009.05.002.

30. Zhao, L.Q., Zhang, F., Guo, J.K., Yang, Y.L., Li, B.B., Zhang, L.X., 2004. Nitric oxide functions as a signal in salt resistance in the calluses from two ecotypes of reed. Plant Physiololgy 134(2): 849-857. http://doi.org/10.1104/pp.103.030023.

31. Zuccarini, P., 2008. Effect of silicon on photosynthesis, water relations and nutrient uptake of Phaseolus vulgaris under $\mathrm{NaCl}$ stress. Biological Plantarom 52(1): 157-160. 


\title{
Effect of Seed Priming by Silicic Acid and Sodium Nitroprusside Solutions on Seed Germination and Seedling Growth of Greenhouse Tomato (Lycopersicom esculentum L. cv. Isabella) under Salinity Stress
}

\author{
N. Ghanaatian ${ }^{1}$, A.H. Aboutalebi Jahromi ${ }^{2 *}$, H. Sadeghi ${ }^{2}$, S. Kalte Jari ${ }^{1}$ \\ and B. Behroznam²
}

(Received: 16 September 2020; Accepted: 5 December 2020)

\begin{abstract}
This investigation was conducted to evaluate the effect of seed pretreatment using silicic acid and sodium nitroprusside on the germination parameters of tomato (Lycopersicom esculentum cv. Isabella) under salinity stress based on a factorial arrangement in a completely randomized design with 5 replications. The first factor, salinity levels, included 0 , 25, 50, 100 and $150 \mathrm{mM}$ sodium chloride $\left(0.067,2.45,5.44,9.52\right.$ and $14.10 \mathrm{dS} \mathrm{m}^{-1}$, respectively); the second one was the chemical pretreatment of the seed with/without $2.5 \mathrm{mM}$ silicic acid solution $(\mathrm{SiA})$, and the third one was the chemical pretreatment of the seeds with/without $100 \mathrm{mM}$ sodium nitroprusside (SNP). Results showed that, due germination percentage, germination rate, seed vigor index and stress tolerance index were all decreased, but application of SiA and SNP improved some factors in Isabella tomato seed germination. Under saline conditions, the use of SiA and SNP had a significant effect on reducing the effects of salinity in the above-mentioned indices. In general, the negative effects of salinity on the seed germination characteristics could be reduced by pretreating tomato seeds with $100 \mu \mathrm{M}$ SNP or $2.5 \mathrm{mM} \mathrm{SiA}$ solution, alone or in combination, under salinity levels up to $100 \mathrm{mM} \mathrm{NaCl}$ (i.e., $9.52 \mathrm{dS} \mathrm{m}^{-1}$ ).
\end{abstract}

Keywords: Germination percent, Germination rate, Seed vigor index, Stress tolerance index.

Background and Objective: Tomato as the most important vegetable produced in the world (1). Tomatoes are classified as a semi-sensitive plant to salinity. Seed germination is usually the most important stage during seedling establishment (2). This investigation was conduction with aim of evaluation the effect of seed pre-treatment using silicic acid (SiA) and sodium nitroprusside (SNP) on germination parameters of tomato cv Isabella under salinity stress. Isabella is one of the most important tomato cultivars that is grown in greenhouse conditions as well as tomato scaffolding (3). In some southern of Iran, cultivation of greenhouse cultivars is done in scaffolding conditions. In this area, there is still a problem with access to suitable water or a desalination device in some areas, and farmers themselves are producing seedlings (4). Seed priming with substances such as SNP and silicic acid can improve the vegetative growth of seedlings after transfer to the main field, so production conditions in the main filed are not always irrigated with suitable water and sometimes occurs with water at high salinity levels. Therefore, seed priming with different materials can adapt the seedling to withstand stress conditions in the main field (5).

Methods: The experiment was carried out as factorial arrangement in a completely randomized design with 5 replications. The first factor was salinity levels include $0,25,50,100$ and $150 \mathrm{mM}$ sodium chloride $(0.067,2.45,5.44$, 9.52 and $14.10 \mathrm{dS} \mathrm{m}^{-1}$, respectively); the second was chemical pretreatment of the seed with/without $2.5 \mathrm{mM} \mathrm{SiA}$ and

1. Department of Horticulture, Science and Research Branch, Islamic Azad University, Tehran, Iran.

2. Department of Horticulture, Jahrom Branch, Islamic Azad University, Jahrom, Iran.

* Corresponding Author, Email: aa84607@gmail.com 
the third was chemical pretreatment with/without $100 \mathrm{mM} \mathrm{SNP.} \mathrm{The} \mathrm{studied} \mathrm{characteristics} \mathrm{were} \mathrm{seed} \mathrm{germination} \mathrm{and}$ rate,seed vigor index, seedling length, seedling fresh and dry weight, and stress index. The obtained data was analyzed using SAS ver. 9.1 software and the means were compared using LSD test $(p<0.05)$.

Results: Based on the results of variance analysis, silicic acid and salinity had a significant effect on all the studied traits but SNP only had a significant effect on seed vigor index. With regard to germination rate and average seedling length, a significant effect between SiA and SNP was observed. There was a significant interaction between SiA and salinity in all traits except germination percentage and stress tolerance index. The interaction between SNP and salinity was significant in all traits. On the other hand, a significant effect was observed between germination rate, seed vigor index and seedling fresh weight. According to the results, due to salinity stress, germination percentage and rate, seed vigor and stress index decreased, but application of SiA and SNP improved some factors in Isabella tomato seed germination. Under salinity conditions, use of SiA and SNP had a significant effect on reducing the effects of salinity on the above indices.

Conclusions: In general, negative effects of salinity on seed germination can be reduced by pre-treating seeds with 100 $\mu \mathrm{M}$ SNP or $2.5 \mathrm{mM}$ SiA solution alone or in combination under salinity levels up to $100 \mathrm{mM} \mathrm{NaCl}\left(9.52 \mathrm{dS} \mathrm{m} \mathrm{m}^{-1}\right)$. The use of SiA significantly increased the germination percentage compared to control plants, although the use of SNP did not have a positive effect. Co-application of SiA and SNP at $100 \mathrm{mM}$ salinity significantly increased germination rate. However, application of these two substances in non-salinity conditions resulted in a significant increase in germination rate. Therefore, the use of these two substances in the absence of salinity is also recommended. Positive effects of the combined use of SiA and SNP in salinity of 50 and $100 \mathrm{mM}$ of $\mathrm{NaCl}$ based on seed vigor index, can be considered as a suitable treatment to overcome salinity stress. Also, the positive effects of the combined use of these two substances in salinity of 25 and $50 \mathrm{mM}$ sodium chloride on the fresh weight of seedlings, as an indicator in improving the vegetative growth of seedlings can be considered.

\section{References:}

1. Faalian, A., Ansari, H., Kafi, M., Alizadeh, A., Moghaddasi M., 2015. Effect of salinity and drought stresses on economical aspect of hydroponic production of greenhouse tomato. Journal of Water Research in Agriculture 29(3): 317-330. (In Persian)

2. Haghighi, M., Afifipour, Z., Mozafarian, M., 2012. The alleviation effect of silicon on tomato seed germination and seedling growth under salinity stress. Vegetable Crops Research Bulletin 76: 119-126. (In Persian)

3. Hassanvand, F., RezaeiNejad, A. Feizian, M., 2017. Effect of silicic acid on some morphological and physiological characteristics of Pelargonium graveolens under $\mathrm{CaCl}_{2}$ salinity stress. Plant Research Journal 30(2): 309-317. (In Persian)

4. Hubbard, M., Germida, J., Vujanovic, V., 2012. Fungal endophytes improve wheat seed germination under heat and drought stress. Botany 90(2): 137-149.

5. Gupta, B., Huang, B., 2014. Mechanism of salinity tolerance in plants: physiological, biochemical, and molecular characterization. International Journal of Genomics 2014: 701596. 